MODELING THE PACIFIC OCEAN

\title{
Modeling the Pacific Ocean on the Computer [Video]
}

Eckart Meiburg $^{\text {a }}$

Keywords: sediment transport, turbulence, waves, ocean modeling, computational fluid dynamics

https://doi.org/10.1525/001c.22191

In fluid dynamics, motions on and below the ocean surface, such as surface and internal (underwater) waves, or along the ocean floor are modeled. Before we can simulate the ocean on a computer, it has to be mathematically divided into separate "control volumes" for which we impose the classic physical conservation principles for mass, momentum, energy, or salinity. Sometimes, billions of these discrete boxes are coupled in a single model. Computer models alongside satellite or field study data, as well as some laboratory experiments help us understand how large-scale events such as underwater avalanches can impair underwater infrastructure such as telecommunication cables or pipelines, how gas and oil reservoirs form below the ocean floor, or how ocean transport of heat, salt, and $\mathrm{CO}_{2}$ affects global climate, ocean temperature, and acidification. Scalability is important for this type of modeling, since computational investigations of ocean flows often start with small systems that are then upscaled into much larger-scale phenomena.

Video available at: https://vimeo.com/527398493

a Eckart Meiburg received his PhD in Mechanical Engineering from the University of Karlsruhe, Germany, in 1985. After appointments at Stanford University, Brown University and USC, he joined UC Santa Barbara in 2000, where he is now a Distinguished Professor of Mechanical Engineering. His research focuses on the field of Computational Fluid Dynamics, with a special focus on environmental and multiphase flows. Eckart is a Fellow of the American Physical Society and of the American Society of Mechanical Engineers. He has received a Presidential Young Investigator Award from the National Science Foundation, a Senior Scientist Award from the Humboldt Foundation, a Senior Gledden Fellowship from the University of Western Australia, and a Shimizu Visiting Professorship at Stanford. He was the Straub Lecturer at the University of Minnesota, and the Probstein Lecturer at MIT. He has held visiting positions in Europe, Australia and the U.S. 


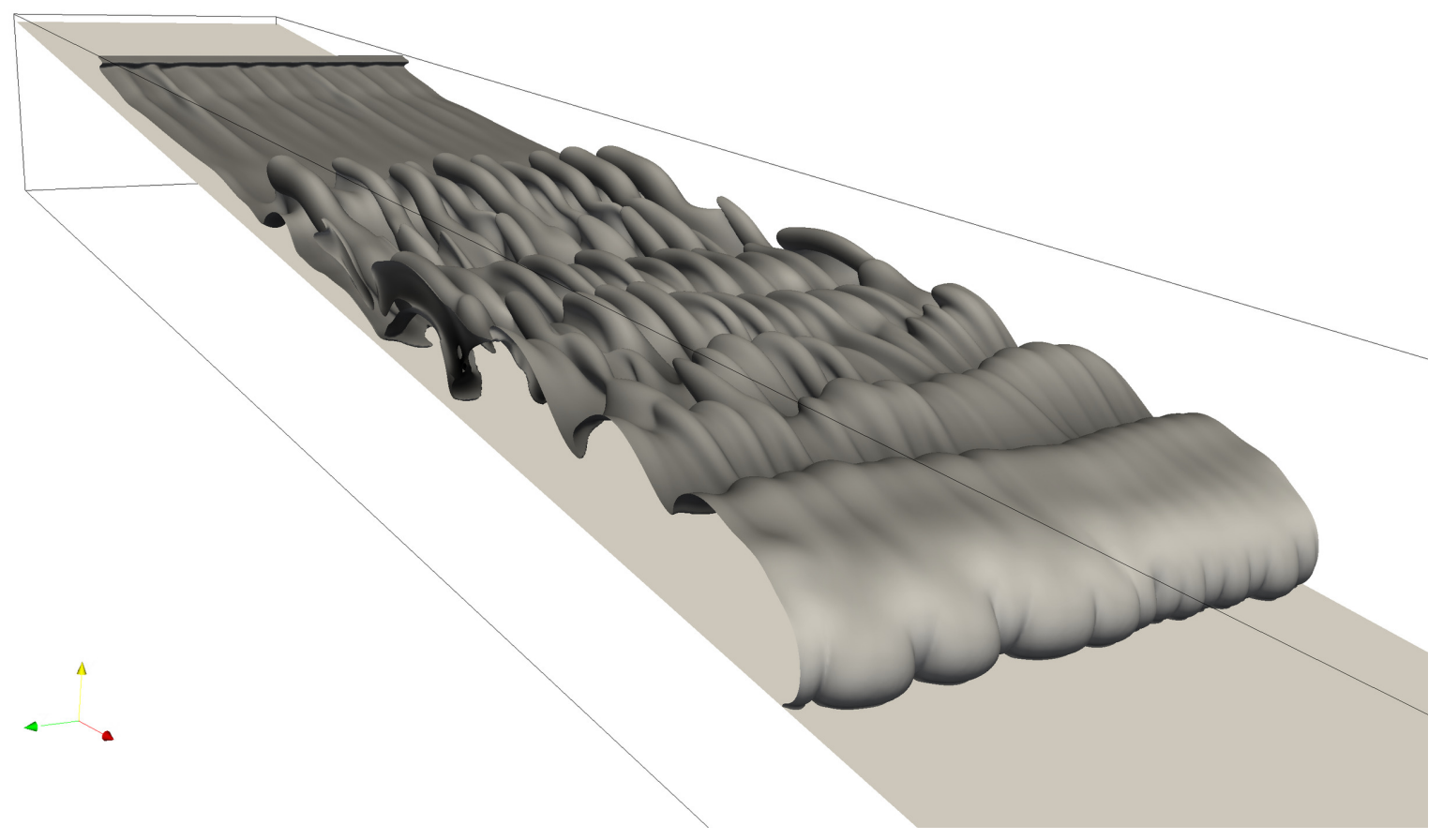

Figure 1: Numerical model of an underwater avalanche

Courtesy of Eckart Meiburg. 